\title{
Establishment of anti-mesothelioma monoclonal antibodies
}

\author{
Natsuko Mizutani ${ }^{1,2}$, Masaaki Abe $^{2}$, Shuji Matsuoka ${ }^{2 *}$, Kazunori Kajino ${ }^{2}$, Midori Wakiya ${ }^{2,3}$, Naomi Ohtsuji ${ }^{2}$, \\ Ryo Hatano ${ }^{4}$, Chikao Morimoto ${ }^{4}$ and Okio Hino ${ }^{2}$
}

\begin{abstract}
Background: Mesotheliomas are aggressive, therapy-resistant tumors that are predicted to increase in incidence at least until 2020. The prognosis of patients with mesothelioma is generally poor because they are typically diagnosed at a late stage and their tumors are resistant to current conventional therapies. For these reasons, improved diagnosis and therapy are urgently required. To address these issues, the aim of our research was to develop novel mesothelioma-specific monoclonal antibodies (mAbs) as diagnostic and therapeutic agents.
\end{abstract}

Methods: To develop anti-mesothelioma mAbs useful for diagnosis and therapy, we repeatedly immunized a BALB/C mouse with viable mesothelioma cells, alternating between those from three mesothelioma cell lines. We hybridized the spleen cells from this immunized mouse with P3U1 myeloma cells. We then screened supernatants harvested from the hybridoma clones by assessing whether they bound to a mesothelioma cell line not used for immunization and altered its morphology. We designed this developmental strategy to reduce the risk of obtaining clonotypic mAbs against a single mesothelioma cell line.

Results: Our newly generated mouse anti-human mAbs immunostained clinical samples of mesotheliomas. One of the newly generated mAbs did not react with any other tumor cell line tested. Two other mAbs significantly inhibited the proliferation of mesothelioma cells.

Conclusion: These newly generated anti-mesothelioma mAbs are potentially useful as diagnostic and therapeutic agents for mesothelioma. Moreover, our novel strategy for establishing antitumor mAbs may facilitate the development of new diagnostic and therapeutic techniques for mesotheliomas and other malignancies.

Keywords: Monoclonal antibody, Mesothelioma, Diagnosis, Therapy, Method

\section{Background}

Mesothelioma is an aggressive tumor that develops from mesothelial cells, which line the pleural, peritoneal, and pericardial cavities. The development of mesothelioma is usually associated with chronic exposure to asbestos fibers $[1,2]$. The worldwide incidence of mesothelioma is increasing and is expected to peak in approximately 2020 because of the long latent period between exposure to asbestos fibers and the appearance of disease [3]. Asbestos continues to be mined in Russia, China, Brazil, Kazakhstan and other countries [4]. Asbestos is still

\footnotetext{
*Correspondence: matsuoka@juntendo.ac.jp

${ }^{2}$ Departments of Pathology and Oncology, Juntendo University School

of Medicine, 2-1-1, Hongo, Bunkyo-ku, Tokyo 113-8421, Japan

Full list of author information is available at the end of the article
}

imported and used in brake pads, gaskets, etc., even in the US [4]. Diagnosis based on chest X-ray and computed tomography $(\mathrm{CT})$ findings must be confirmed by cytologic serous effusion examination or biopsy [5-7].

Immunohistochemistry has significantly enhanced the accuracy of cytology, although reaching a diagnosis remains frequently difficult [8-10]. Although many diagnostic procedures are available, no single test unambiguously distinguishes mesothelioma from other carcinomas or even benign from malignant cells. The correct combination of antibodies used to detect positive or negative markers should be employed and a comprehensive assessment of the staining results must be conducted [11]. 
Mesothelioma is categorized histologically as epithelioid, sarcomatoid, biphasic, and desmoplastic, among others [9]. The histological subtypes help predict prognosis and the choice of treatment. Therefore, it is important to analyze pathological tissue using an appropriate combination of antibodies for diagnosis and classification. Nevertheless, many cases are difficult to diagnosis [12-16].

Although an anti-CD26 mAb is a promising candidate, no effective molecular target for therapy exists $[17,18]$. Therefore, the development of novel anti-mesothelioma mAbs may facilitate diagnosis and serve as therapeutic agents. Subsequent to the development of mAbs by Köhler, Milstein, and Jerne in 1975 [19], excessively large number of mAbs were generated as diagnostic [20,21] or therapeutic reagents [22].

Diagnostic or therapeutic mAbs are now typically generated by immunizing mice with synthetic peptides or target antigens that are purified to some extent [23, 24]. Except for nude or SCID mice, mice reject inoculated live malignant human tumor cells. During the first or second challenge, tumor cells may be primarily killed by NK and CD8 cytotoxic T cells or ingested by macrophages. However, during the course of repeated immunizations, mouse B cells are generated that produce antibodies against the tumor cells. These antibodies probably make a major contribution to the rejection of the tumor cells. This hypothesis served as the rationale for our experiments that were aimed at establishing anti-mesothelioma mAbs. We report here the generation of anti-human mesothelioma mAbs for diagnosis and treatment. This was accomplished by immunizing a mouse with live mesothelioma cell lines. The hybridomas were selected for their ability to produce antibodies that bound to mesothelioma cell lines not used for immunization. Some of these newly established mAbs reacted specifically with mesothelioma cells or inhibited their proliferation.

\section{Methods \\ Mice}

Female BALB/c mice (6-8 weeks of age) were purchased from Charles River Japan (Yokohama, Japan) and housed in a specific pathogen-free facility in micro-isolator cages. Animal experiments were conducted following protocols approved by the Animal Care Committee of Juntendo University of Medicine.

\section{Cells}

The human mesothelioma cell lines ACC-MESO-1 and ACC-MESO-4 were purchased from the RIKEN Cell Bank (Ibaraki, Japan), JMN was a kind gift from Dr. Brenda Gerwin and others (NCI-H226, MSTO-211H, NCI-H28 and NCI-H2452) were purchased from the
American Type Culture Collection (ATCC) (Manassas, VA). The lung cancer cell lines (A549, PC9, Lu24, and WA-hT), and the HuH-7 (hepatocellular carcinoma), MKN1 (gastric cancer), OVK18 (ovarian cancer), VMRC$\mathrm{RCW}$ (renal cell carcinoma) cell lines were purchased from the RIKEN Cell Bank. The MCF7 (breast cancer), KP3 (pancreatic cancer), and HCT 116 (colon cancer) cell lines were purchased from ATCC. All cells were cultured and maintained in RPMI-1640 medium (GIBCO, Grand Island, NY) supplemented with $10 \%$ heat-inactivated fetal calf serum.

\section{Antibodies}

The mouse anti-HLA class I (HLA class-A, B, C) mAb (clone: W6/32) was purchased from Harlan Laboratories Inc. (IN). Alexa Flour ${ }^{\circledR}$ 488-conjugated goat anti-mouse IgG was purchased from Invitrogen (CA). Mouse IgG was purchased from Abcam (Cambridge UK). The mAbs for WT-1 (clone: 6F-H2), Calretinin (clone: DAK-Calret 1), Podoplanin (clone: D2-40), Cytokeratin 5/6 (clone: D5/16 B4), EMA (clone: E29), Carcinoembryonic Antigen (CEA) (clone: II-7), TTF-1 (clone: 8G7G3/1), and Epithelial-Related Antigen (clone: Moc-31) were purchased from DAKO. The mAb against Mesothelin (clone: 22A31) and anti-GLUT-1 polyclonal Ab were purchased from IBL (Japan). Anti-CD26 mAbs (clone 1F7, 5F8) were established in our laboratory [25].

Anti-CD25 mAb (clone: BC96) and mouse Ig G1 isotype control (MOPC-21) were purchased from TONBO biosciences (CA).

\section{Generation of mAbs against mesothelioma cells}

An eight-week-old female BALB/c mouse was immunized alternately using intraperitoneal injections of $2-5 \times 10^{6}$ living cells derived from the mesothelioma cell lines ACC-MESO4, MSTO-211H, and NCI-H226 every 2 weeks for 3 months. Three days after the last immunization, spleen cells were fused with P3U1-nonproducing myeloma cells using polyethylene glycol 4000 (Merck, Darmstadt, Germany) and cultured in RPMI1640 supplemented with $10 \%$ fetal calf serum (FCS, Japan Bioserum, Fukuyama, Japan), 5 \% BriClone (NICB, Dublin, Ireland), and HAT (Invitrogen, Tokyo, Japan) in the wells of 96-well flat-bottom plates (Costar, Corning Incorporated, Corning, NY). Hybridoma supernatants were screened for reactivity with the mesothelioma NCI-H2452 cells, which were not used for immunization. Light microscopy revealed morphological changes and an aggregation of target cells induced by incubation with supernatants of hybridoma clones after $72 \mathrm{~h}$. The reactivity of hybridoma supernatants for the other mesothelioma cell lines was also determined. Four hybridomas, JMAM1-4, were selected and cloned using limiting 
dilution. The isotype of these mAbs was IgG1, and they cross-reacted widely with mesothelioma cell lines.

\section{Flow cytometric (FACS) analysis}

The expression of the molecular target(s) of the newly established mouse anti-human mesothelioma mAbs was determined using a BD LSRForessa ${ }^{\mathrm{TM}}$ cell analyzer (BD Bioscience, CA, USA). Briefly, the human mesothelioma cell lines and the cell lines derived from other tumors were incubated with the supernatants of hybridomas and then with Alexa Flour ${ }^{\circledR}$ 488-conjugated rat anti-mouse IgG (BD Bioscience) on ice.

\section{Inhibition test}

NCI-H226 cells were first incubated with already known existing Abs and further incubated with Alexa Flour ${ }^{\circledR}$ 488-labeled JMAM mAbs.

\section{Immunocytochemistry}

Samples of pleural effusions submitted to the Department of Pathology, Juntendo University, were used for immunohistochemistry and other histological staining procedures. Three representative cases of cytologically diagnosed mesothelioma were used for immunohistochemistry, and all cases were stained with positive and negative antibody panels of diagnostic antibodies to confirm the diagnosis of mesothelioma. Cell smears were fixed in $95 \%$ ethanol for Papanicolaou and immunostaining, or air-dried for May-Grunwald-Giemsa staining. Cell sediments were fixed with ethanol and embedded in paraffin for immunostaining. Sections were deparaffinized using three changes of xylene and rehydrated with a graded series of ethanol concentrations. Endogenous peroxidase was inactivated with $0.3 \% \mathrm{H}_{2} \mathrm{O}_{2}$ in phosphatebuffered saline for $10 \mathrm{~min}$. Samples were incubated with the novel anti-mesothelioma mAbs JMAM1-4 at $4{ }^{\circ} \mathrm{C}$ overnight in a humidified chamber, followed by the addition of EnVision ${ }^{\mathrm{TM}}+$ DualLink (DAKO) and 3.3'-diaminobenzidine (Dojindo Laboratories) as the chromogen. Cell smears and cell-block sections were counterstained to reveal nuclei using Mayer's hematoxylin. For all cases, we stained cell block sections using antibodies against EMA, Podoplanin, GLUT-1, Calretinin, WT-1, Cytokeratin 5/6, Mesothelin, CEA, TTF-1, and epithelial-related antigen to confirm the diagnosis of mesothelioma (Table 1).

\section{In vitro proliferative assay of mesothelial cells incubated with mAbs}

MSTO- $211 \mathrm{H}$ cells $\left(1 \times 10^{4}\right.$ cells/well $)$ were incubated with $10 \%$ FCS-RPMI supplemented with $0.005-0.4 \mu \mathrm{g} /$ $\mathrm{ml}$ of JMAM1-4 mAbs for $48 \mathrm{~h}$ at $37^{\circ} \mathrm{C}$ in an atmosphere containing $5 \% \mathrm{CO}_{2}$. The culture was pulsed with $0.5 \mu \mathrm{Ci}$ of tritiated thymidine, $\left[{ }^{3} \mathrm{H}\right]-\mathrm{TdR}$, for the final $24 \mathrm{~h}$. The incorporation of $\left[{ }^{3} \mathrm{H}\right]-\mathrm{TdR}$ was determined using scintillation counting. Data are expressed as the mean \pm standard deviation (SD) of triplicate samples and represent three separate experiments.

\section{Wound-healing assay}

Mesothelioma NCI-H226 cells were seeded in 6-well plates (Corning) and grown to $90 \%$ confluence in RPMI plus $10 \%$ FCS. The cell monolayer was wounded with the tip of an Eppendorf P200 pipette. After wounding, the wells were washed with media to remove dead cells and debris. The wells were treated with either $3 \mu \mathrm{g} / \mathrm{ml}$ of anti-mesothelioma mAbs (JMAM1-4) or a control IgG $(3 \mu \mathrm{g} / \mathrm{ml})$ and cultured further. The wound closure was observed after $24 \mathrm{~h}$.

\section{Cell invasion assay}

For the cell invasion test, a Corning Matrigel Invasion Chamber $(8-\mu \mathrm{m}$ pore size, coated with Matrigel; Discovery Labware Inc., Bedford, MA, USA) was placed into the wells of 24-well culture plates; RPMI-1640 medium with $10 \%$ serum and JMAM1-4 mAbs (each $10 \mu \mathrm{M}$ ) were added into the lower chamber; then, $2 \times 10^{4} \mathrm{NCI}$ $\mathrm{H} 226$ cells in serum-free RPMI-1640 medium was added to the upper chamber and cultured at $37^{\circ} \mathrm{C}$. After $15 \mathrm{~h}$ of incubation, the cells on the upper surface of the filter membrane that had not migrated were gently scraped away with a cotton swab. The invading cells on the lower surface of the filter membrane were fixed with methanol, stained with Diff-Quick ${ }^{\mathrm{TM}}$ (Sysmex), and counted as described above. All tests were performed in triplicate.

\section{Statistical analysis}

The data were analyzed using Student's $t$ test. The results are expressed as the mean \pm SD and $P$ values of $<0.05$ were considered significant. Statistical analyses were performed using SPSS 14.0 software (IBM, NY).

\section{Results}

Morphological changes of mesothelioma cell lines induced by the newly generated mAbs

We found that the newly generated four mAbs reproducibly induced morphological changes in a mesothelioma cell line that was not used for immunization. Light microscopy revealed that the morphology of the NCIH2452 cells changed from spindle-shaped to round, and the numbers of these cells decreased after incubation with JMAM1-4 mAbs for $72 \mathrm{~h}$ compared with control mouse IgG (Fig. 1a, upper column). These morphological changes indicated that the mAbs bound the mesothelial cell lines. These findings were also reproduced using MSTO-211H cells that were used for immunization 
Table 1 Antibodies used in this study and immunocytochemical reactivity

\begin{tabular}{|c|c|c|c|c|c|c|c|}
\hline Antibody & Clone & Source & Dilution & Specimen & Case 1 & Case 2 & Case 3 \\
\hline JMAM1 & & Our labolatory & Undiluted cell supernatant & Cell smear & + & + & + \\
\hline JMAM2 & & Our labolatory & Undiluted cell supernatant & Cell smear & + & + & + \\
\hline JMAM3 & & Our labolatory & Undiluted cell supernatant & Cell smear & + & + & + \\
\hline JMAM4 & & Our labolatory & Undiluted cell supernatant & Cell smear & + & + & + \\
\hline WT-1 & $6 \mathrm{~F}-\mathrm{H} 2$ & DAKO & $1: 200$ & Cell block & + & \pm & + \\
\hline Carletnin & Dak-Calret 1 & DAKO & $1: 100$ & Cell block & + & + & + \\
\hline Mesothelin & $22 \mathrm{~A} 31$ & $\mathrm{IBL}$ & 1:1000 & Cell block & + & + & + \\
\hline Podoplanin & D2-40 & DAKO & $1: 200$ & Cell block & + & + & + \\
\hline CK5/6 & D5/16B4 & DAKO & $1: 50$ & Cell block & + & + & + \\
\hline EMA & E29 & DAKO & $1: 100$ & Cell block & + & + & + \\
\hline GLUT-1 & $5 B 12.3$ & $\mathrm{IBL}$ & $1: 1000$ & Cell block & + & + & + \\
\hline CEA & $\|-7$ & DAKO & $1: 50$ & Cell block & - & - & - \\
\hline TTF-1 & $8 G 7 G 3 / 1$ & DAKO & $1: 100$ & Cell block & - & - & - \\
\hline Epithelial-related antigen & Moc-31 & DAKO & $1: 100$ & Cell block & - & - & - \\
\hline
\end{tabular}

(Fig. 1a, lower column). Furthermore, these mAbs aggregated MSTO- $211 \mathrm{H}$ cells. Taken together, these findings indicate that the newly established mAbs reacted with the mesothelial cell lines.

\section{Analysis of the binding of mAbs to the mesothelial cell lines}

The reactivity of the mAbs against the mesothelial cell lines was determined using FACS analysis. JMAM1, JMAM2 and JMAM3 mAbs stained the epithelial (ACCMESO-4, JMN) and sarcomatous (MSTO-211H, H2452, $\mathrm{H} 28$ and MESO-1) cell lines. In contrast, JMAM4 stained the epithelial cell lines but not the sarcomatous cell lines (Fig. 1b).

\section{Competitive inhibition of JMAM mAbs with established mAbs}

To determine whether the newly established JMAM mAbs bind to the same epitope of the already existing Abs, we performed an inhibition test by flow cytometry.

NCI-H226 cells were incubated with JMAM mAbs followed by staining with existing Abs already known to bind to mesothelioma [anti-calretinin, anti-podoplanin (D2-40), anti-GLUT-1, anti-CD25 (BC96), anti-CD26 (1F7, 5F8), anti-C-ERC/mesothelin (22A31)]. (Fig. 2).

Anti-calretinin was able to partially inhibit the staining of the NCI-H226 mesothelioma cell line with JMAM2 $\mathrm{mAb}$. This result indicates that the JMAM2 determinant is strongly related to calretinin; however, the other JMAM mAbs have no relationship with already existing Abs, they may bind to mesothelioma cells.

\section{Analysis of the binding of $\mathrm{mAbs}$ to other tumor cell lines}

Using FACS analysis, we next determined whether the mAbs bound to lung cancer cell lines. Binding of JMAM1 to epithelial-type lung cancer cell lines (A549 and PC9) was not detectable. In contrast, it bound to the small-cell lung cancer cell lines WA-hT and Lu24. The extent of binding of JMAM2 and JMAM3 mAbs to lung cancer cell lines varied. The JMAM4 mAb did not bind to any of the lung cancer cell lines (Fig. 3a).

To determine the cross-reactivity of these novel antimesothelioma mAbs to cell lines derived from tumors other than those of the lung, we used FACS analysis to determine their ability to react with MCF7 (breast cancer), HuH-7 (liver cancer), KP3 (pancreatic cancer), MKN-1 (gastric cancer), HCT 116 (colon cancer), OVK18 (ovarian cancer), and VMRC-RCW (renal cell carcinoma) cell lines. The JMAM1 mAb only cross reacted with the VMRC-RCW cell line. JMAM4 mAbs did not react detectably with any of these carcinoma cell lines. The JMAM2 mAb slightly or significantly stained all carcinoma cell lines tested. The JMAM3 mAb did not stain the liver or pancreatic cancer cell lines; however, it lightly stained a gastric cancer cell line and strongly stained breast and colon cancer cell lines (Fig. 3b). Taken together, these data indicate that the JMAM1 mAb distinguished mesothelioma and small-cell lung cancer cells from epithelial lung cancer cells as well as any other cancer cells derived from these tissues except for renal cell carcinoma. These data also suggesting that JMAM4 mAb may distinguish epithelial mesotheliomas from all other cancers. 
a

$\mathrm{NCl}-$

$\mathrm{H} 2452$

MSTO-

$211 \mathrm{H}$
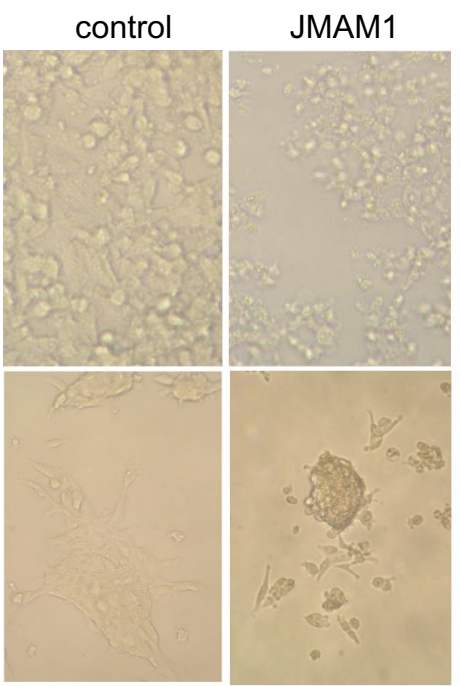

b

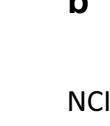

H226

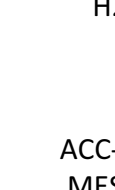

MESO-4

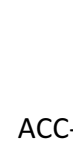

ACC-MESO-1

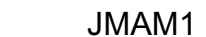

JMAM2
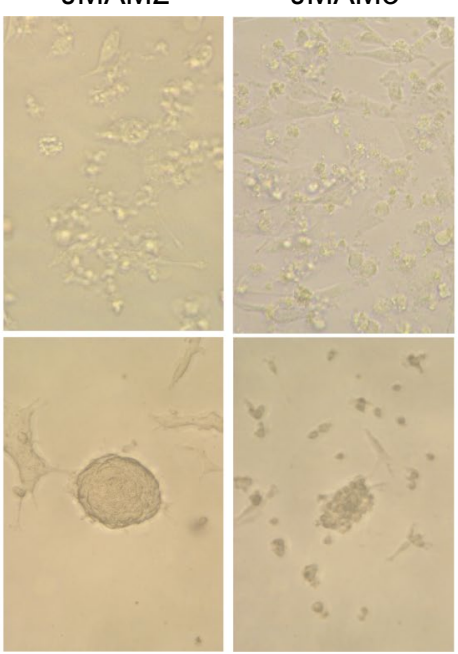

JMAM3

JMAM4

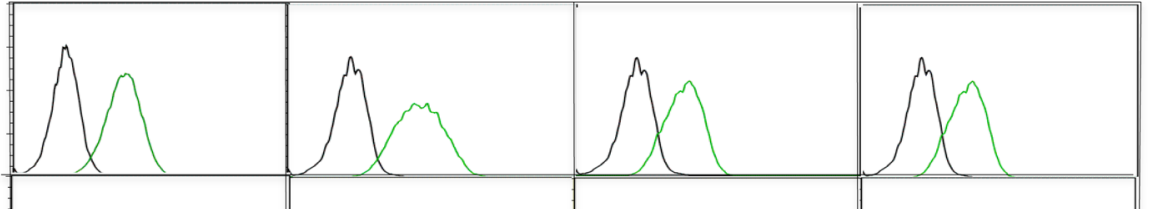

JMN

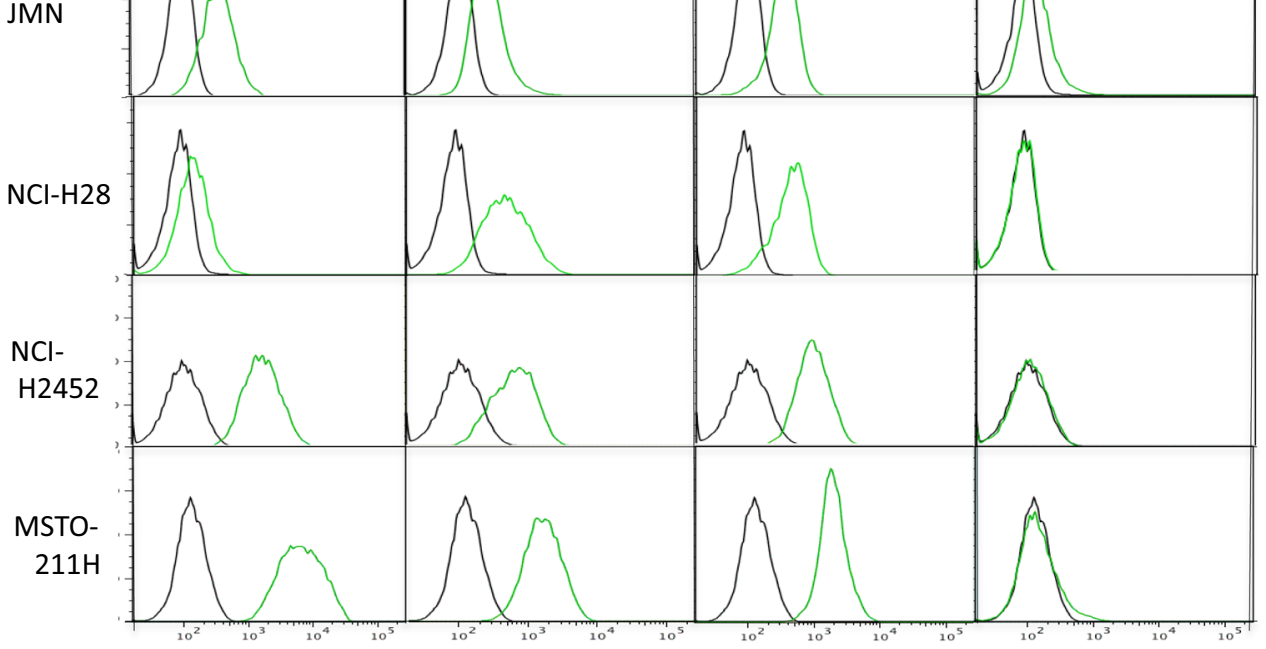

Fig. 1 Reactivity of JMAM mAbs with mesothelioma cell lines. a Morphological changes by JMAM mAbs. NCl-H2452 cells were incubated with hybridoma supernatants for $72 \mathrm{~h}$ and observed using visible light microscopy. RPMI-1640 medium with $10 \%$ FCS served as the control (upper column). These findings were also reproduced using MSTO- $211 \mathrm{H}$ cells (lower column). b Flow cytometry analysis of JMAM mAb reactivity. Mesothelioma cell lines were incubated with the hybridoma supernatant (green histogram) or control mouse lgG (black histogram), subsequently stained with Alexa Flour ${ }^{\circledR}$-488 labeled anti-mouse IgG Ab and analyzed using flow cytometry 


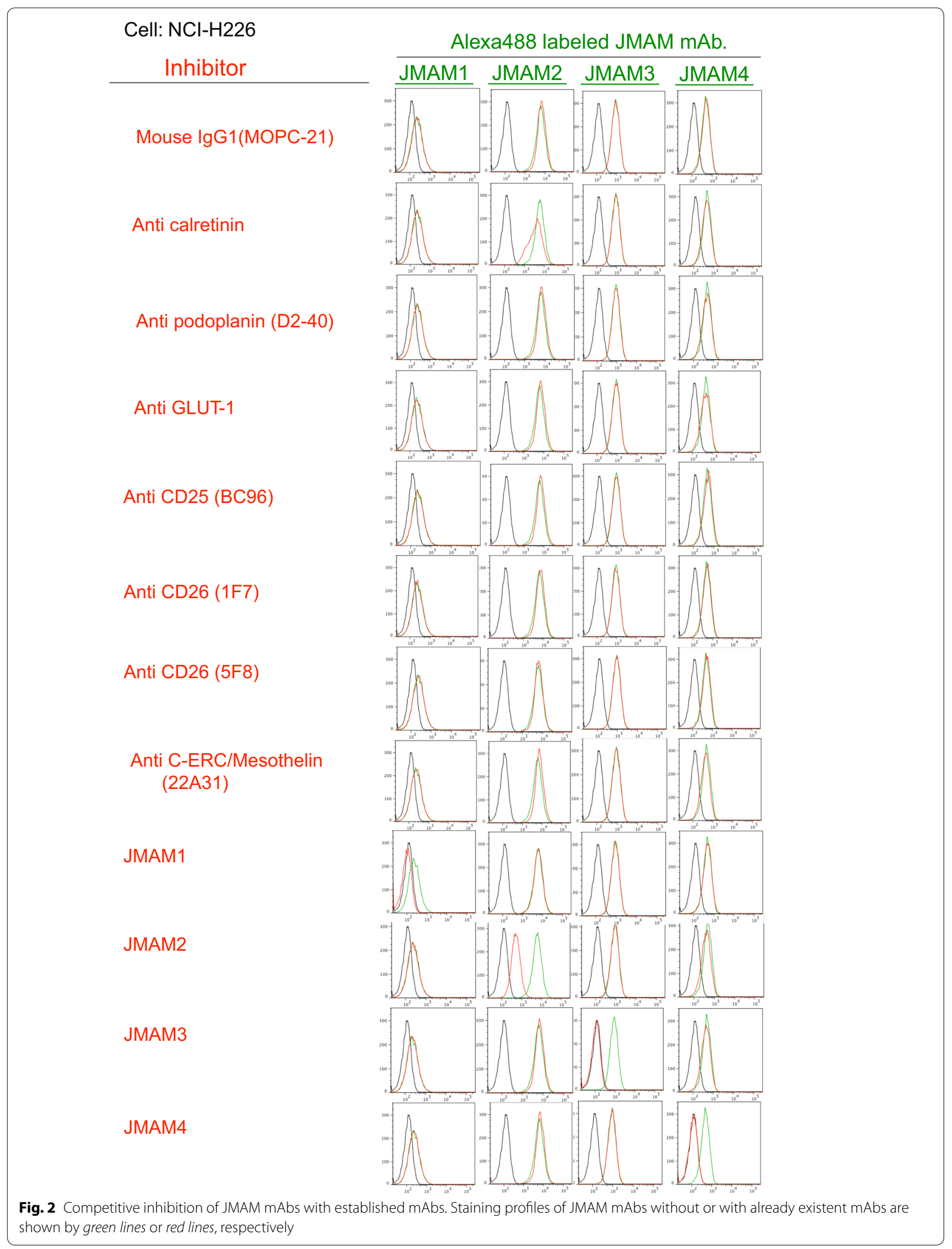



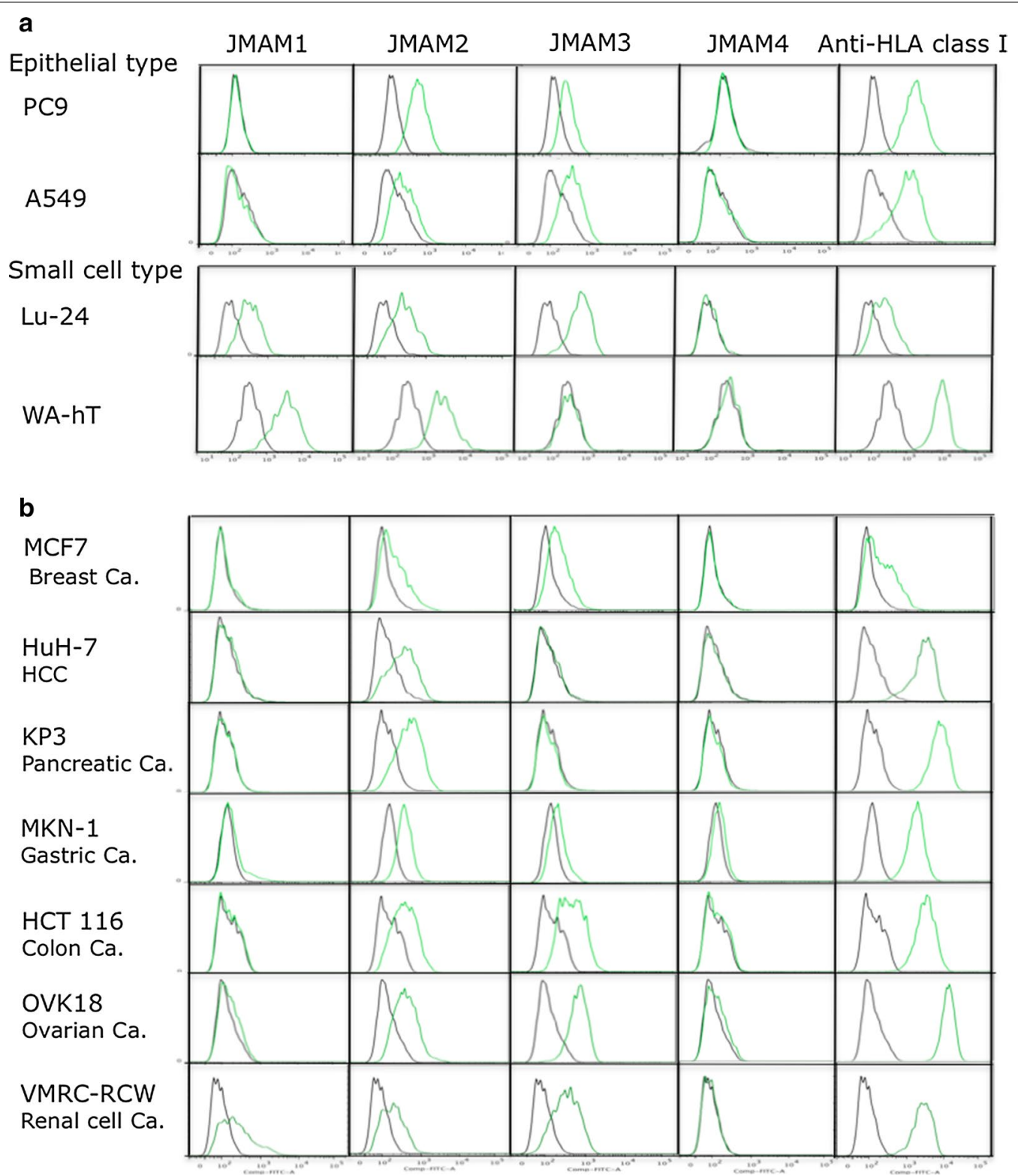

Fig. 3 Reactivity of JMAM mAbs with other cell lines. Epithelial-type and small-cell-type lung cancer (a) and other cancer cell lines (b) were incubated with hybridoma supernatants (green histogram) or control mouse lgG (black histogram), subsequently stained with Alexa Flour ${ }^{\circledR} 488$-labeled anti-mouse lgG Ab and analyzed using flow cytometry

\section{Analysis of mesotheliomas by $\mathrm{mAbs}$}

To determine whether these newly generated mAbs were suitable for immunohistochemical staining of formalinfixed tissue sections, we used them to analyze surgically resected mesothelioma tissue specimens. Unfortunately, we did not detect staining of formalin-fixed paraffinembedded tissue specimens (data not shown). The antigens recognized by the mAbs might have been masked or antigenically inactivated by formalin fixation.
Body fluid retention is one of the symptoms of many patients with malignant mesothelioma who are often diagnosed with mesothelioma by body fluid cytological examination. Therefore, we investigated whether the mAbs reacted with cytological samples using body fluid specimens that were fixed with ethanol. We analyzed specimens from three patients with malignant mesothelioma and those from patients suspected to have malignant mesothelioma (Fig. 4). All materials were prepared from pleural effusions. 


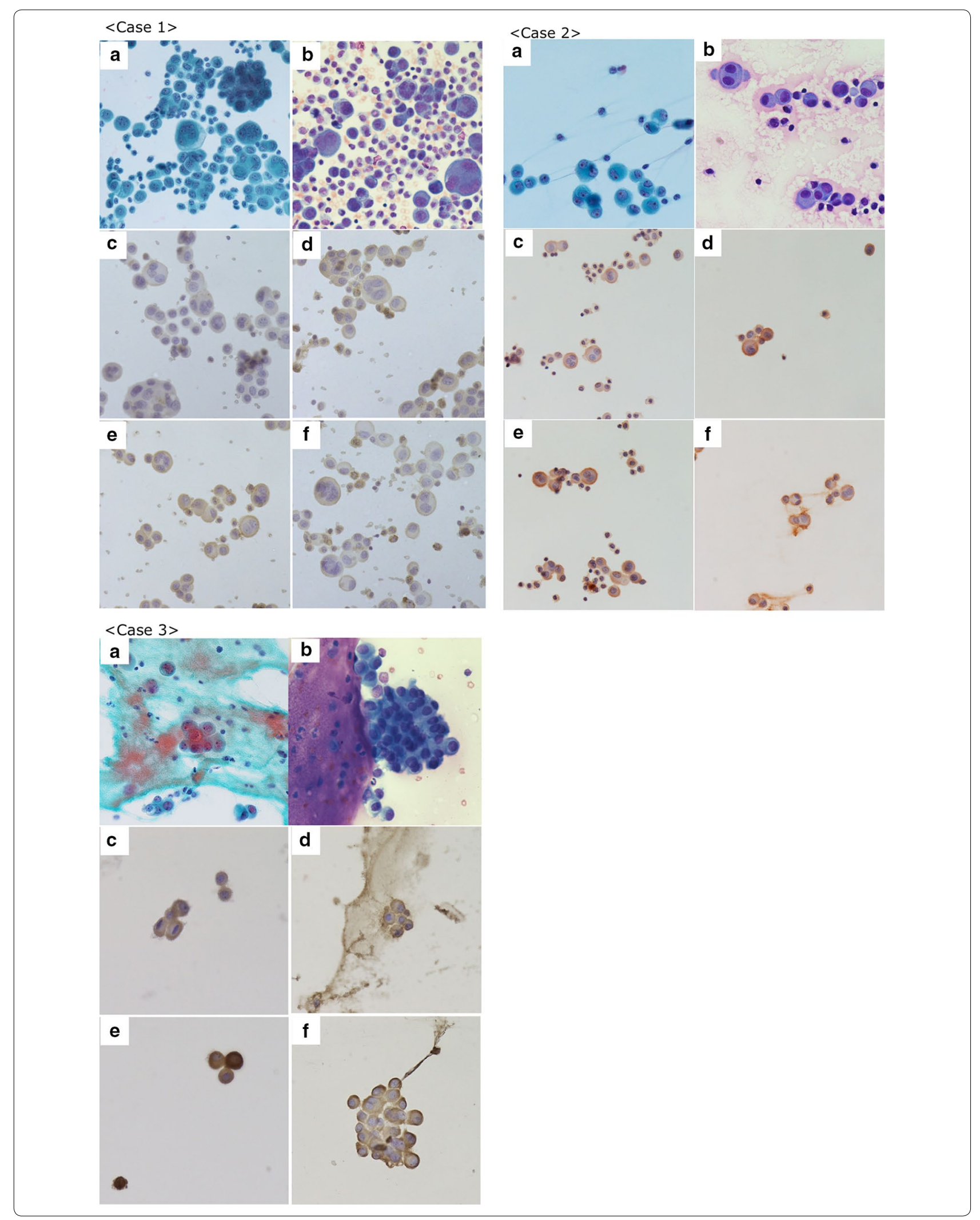


(See figure on previous page.)

Fig. 4 Immunocytochemistry of clinical cases. a Papanicolaou; b Giemsa; c JMAM1; d JMAM2; e JMAM3; f JMAM4. Original magnification 400x. The malignant mesothelioma smear specimens, prepared from pleural effusions. Case 1 JMAM1, JMAM2, JMAM3, and JMAM4 mAbs stained membranes. JMAM2 mAb stained membranes and the cytoplasm. Case 2 All mAbs stained membranes. Case 3 JMAM1 and JMAM4 mAbs stained membranes;

JMAM2 and JMAM3 mAbs stained membranes and cytoplasm

Case 1 Many cell clusters were present, including tight and loose clusters with flattened cellular borders. Individual cells showed wide variation in shape and size, ranging from small to very large. The JMAM1-4 mAbs stained membranes, whereas the JMAM2 mAb stained the cytoplasm and the membrane.

Case 2 The few malignant cells present were judged Class III by Papanicolaou classification. All mAbs stained membranes clearly.

Case 3 Present were small to large clusters with knobby borders and a single-cell population. These cells had low nuclear: cytoplasmic ratios, but occasionally showed macronucleoli. The staining of membranes by mAbs JMAM1-4 was distinct. Antibodies against Podoplanin, Mesothelin, EMA, and GLUT-1 stained cell-block specimens, which confirmed these atypical cells as derived from mesothelioma (Table 1). Because JMAM1-4 mAbs stained the membranes of all mesothelioma specimens tested, they may be useful for the cytological testing of pleural effusions of patients with mesothelioma.

\section{Histopathology and cytology of lung and mesothelial cells} Reactive normal pleura and lung immunoreactive features are shown in Fig. 5. Reactive pleural effusion mesothelial cells stained with JMAM mAbs (a); however, normal pleural mesothelium and lung tissue did not stain with JMAM mAbs (b, c).

\section{Analysis of the effects of mAbs on the proliferation of mesothelioma cells}

We next tested whether the mAbs inhibited the proliferation of the MSTO-211H mesothelioma cell line (Fig. 6). The JMAM1 and JMAM3 mAbs inhibited the proliferation of MSTO-211H cells as a function of their dose. Thus, proliferation was reduced by at least 50 and $40 \%$ by $0.4 \mu \mathrm{g} / \mathrm{ml}$ of JMAM1 or JMAM3 mAbs, respectively.

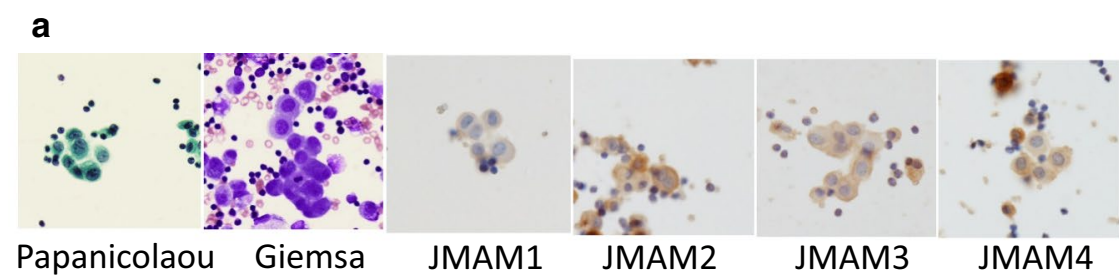

b

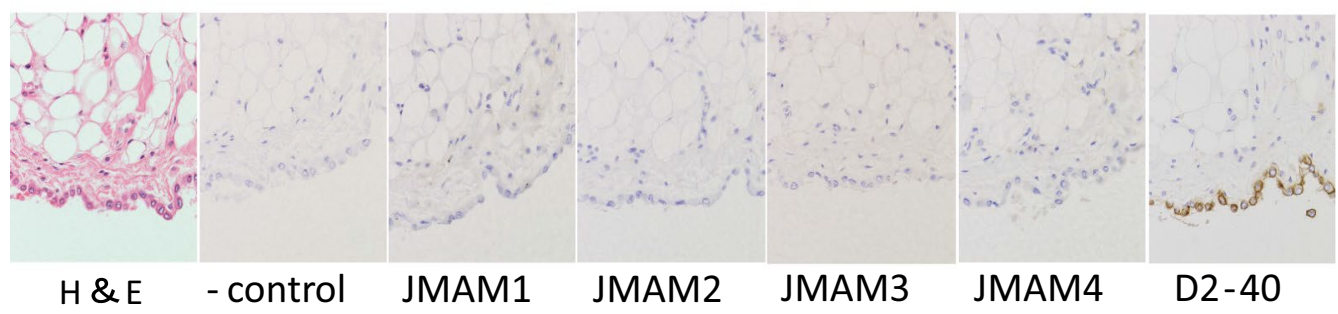

C

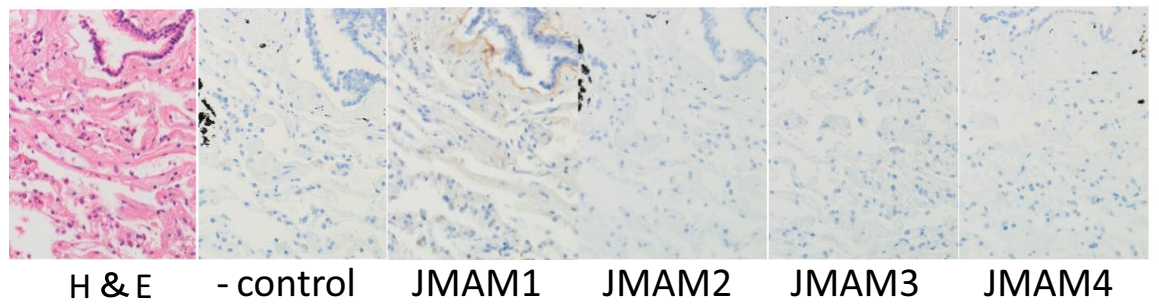

Fig. 5 Histopathology and cytological findings of reactive mesothelial cells, normal pleura and lung, with immunoreactive features. a Pleural effusion (reactive mesothelial cells, 1000x). b Normal pleura (400x). c Normal lung (400x) 

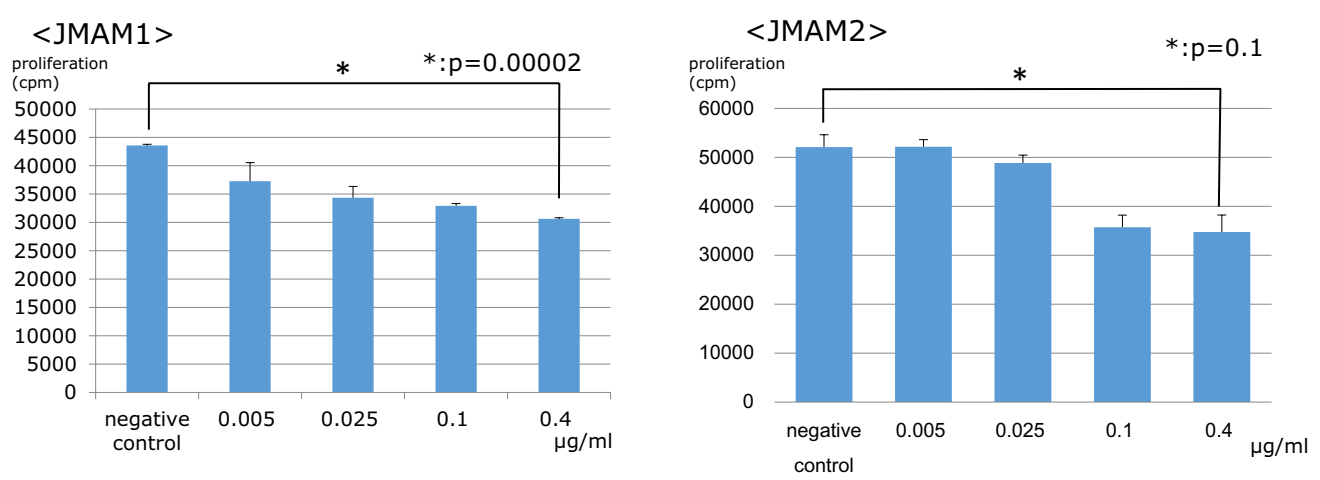

\section{$<$ JMAM3 $>$}
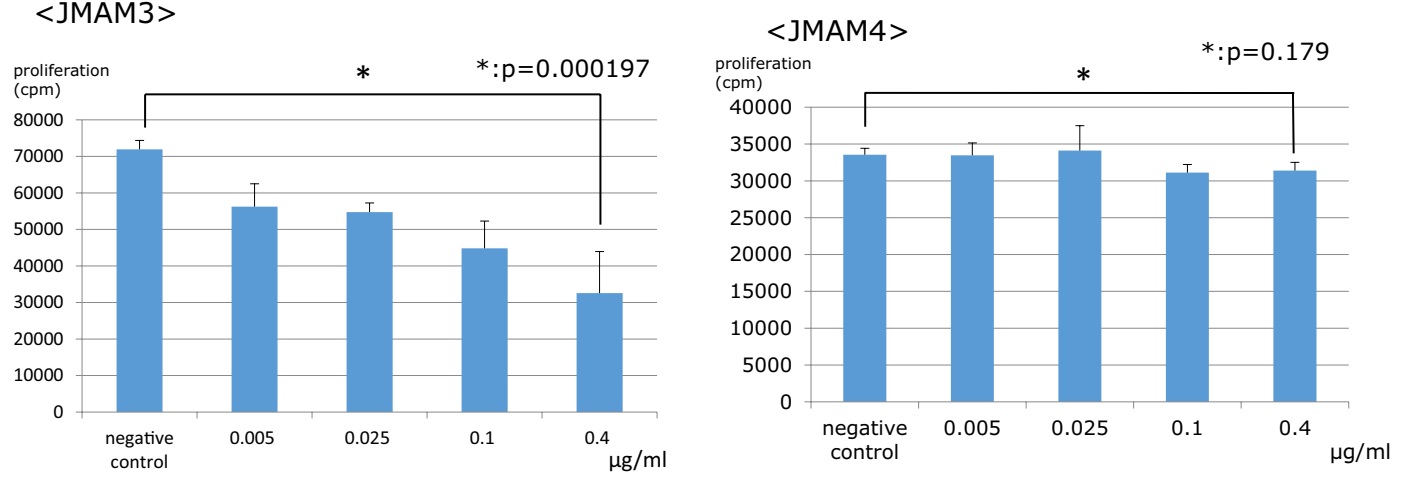

Fig. 6 Proliferation of MSTO-211 H cells in the presence of JMAM1-4 mAbs. JMAM1-4 mAbs were added at the indicated concentrations to cultures of MSTO-211 H mesothelioma cells. JMAM1, P < 0.05; JMAM2, P = 0.1; JMAM3, P < 0.05; JMAM4, P $=0.18$

The JMAM2 mAb inhibited cell proliferation to some extent. The JMAM4 mAb did not inhibit the proliferation of MSTO-211H cells. These results indicate that JMAM1 and JMAM2 mAbs may be useful for treating patients with mesothelioma, at least those with the epithelioid phenotype.

\section{Analysis of the effect of JMAM mAbs on migration of mesothelioma cells}

Cell motility is an essential process of tumor metastasis and progression. Therefore, we investigated whether the mAbs would affect the migration of mesothelioma cells using a wound-healing assay. The anti-mesothelioma mAbs JMAM1, JMAM2, and JMAM3 significantly inhibited the ability of NCI-H226 cells to migrate to and close an experimentally induced wound (Fig. 7). These results show that the anti-mesothelioma mAbs inhibited the motility of mesothelioma cells and suggest that the JMAM1-4 mAbs may possess a remarkable ability to inhibit the progression of mesotheliomas.

\section{Analysis of the effect of JMAM mAbs on invasion of mesothelioma cells}

We assessed the cell invasion ability of mesothelioma NCI-H226 cells. Significant inhibition of invasion was observed by JMAM mAbs compared with control mouse
IgG1 Ab (Fig. 8). JMAM1 mAb significantly decreased the trans membrane migration of NCI-H226 cells compared with cells treated with the mouse IgG1 isotype control.

\section{Discussion}

Differentiating between a mesothelioma and a papillary adenocarcinoma is sometimes very difficult [25]. Clinicians recommend that the definitive diagnosis of mesothelioma may be achieved using immunohistochemical analysis of cytological or histological specimens with currently available antibodies [8]. Many mAbs are developed for the diagnosis of and therapy for mesothelioma. Previously, we focused on CD26 as a novel therapeutic target for mesothelioma and have developed a humanized anti-CD26 mAb (clone: YS110), which is currently being evaluated in a phase I clinical trial for patients with malignant mesothelioma [26]. We also developed anti-human CD26 mAbs (clone: 1F7, 5F8) that clearly and reliably detect the denatured CD26 molecule in formalin-fixed paraffin-embedded tissue [27]. Although many antibodies are available to aid diagnosis, no single antibody can unambiguously distinguish mesotheliomas from other carcinomas. Anti-CD26 mAb reacts with epithelial and sarcomatoid mesotheliomas. However, anti-CD26 mAb also reacts with several other tumor cells and lymphocytes. 

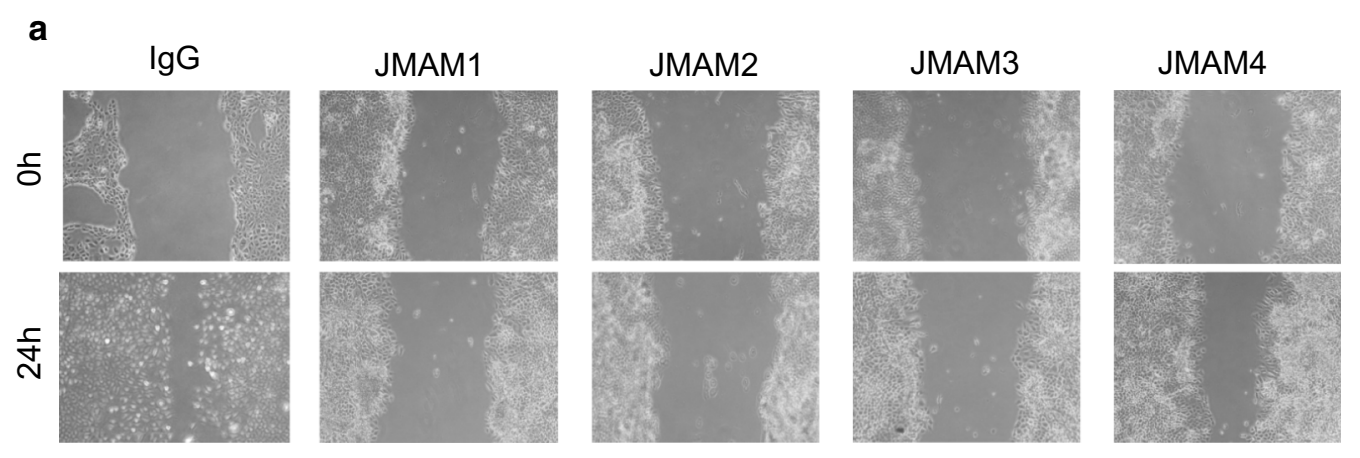

b

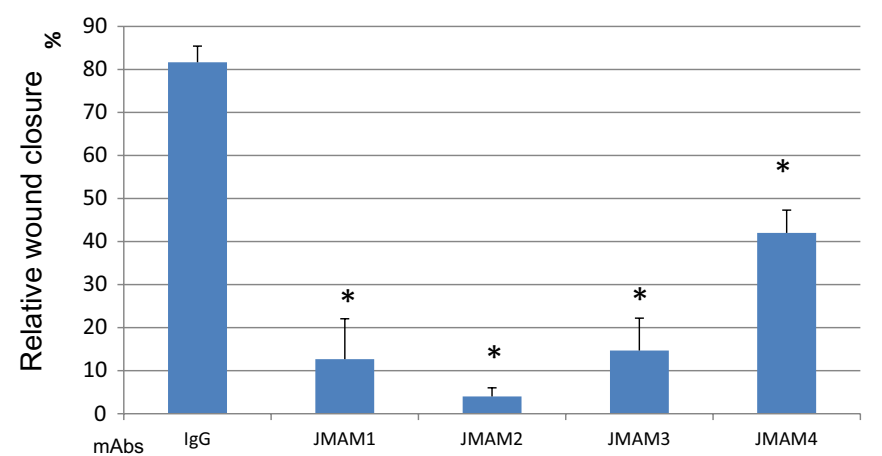

Fig. 7 Wound-healing assays. a Representative images of wound closure assays after NCl-H226 cells were incubated with anti-mesothelioma antibodies or control mouse IgG. b The extent of wound closure was calculated by analyzing the scratched area covered by the cells after $24 \mathrm{~h}$ using ImageJ software. The data were normalized to the control values. The data are represented as the mean \pm SD of three independent experiments. ${ }^{*} \mathrm{P}<0.05$; treated versus IgG control

Anti-mesothelin mAbs react with epithelial but not sarcomatoid mesotheliomas [13]. In contrast, JMAM1, JMAM2, and JMAM3 mAbs react with both subtypes. Anti-mesothelin $m$ Abs react with renal cell carcinomas and pancreatic and ovarian cancers [28-30], unlike the JMAM4 mAbs that did not react with lung, ovarian, or renal cell carcinomas or any of the other cancer cell lines tested. JMAM1 $\mathrm{mAb}$ did not cross-react with other carcinoma cell lines except for small-cell-type lung cancer cell lines and renal cell carcinoma cell lines. Taken together, our newly generated mAbs are more specific for mesothelioma than other diagnostic mAbs and may be helpful in the differential diagnosis of mesothelioma. Novel anti-mesothelioma mAbs may either serve as tools to diagnose mesotheliomas as stand-alone reagents or together with other diagnostic mAbs.

It is now commonly accepted that therapeutic mAbs dramatically improve the treatment of cancer patients. However, after repeated therapy, not all patients respond to therapeutic mAbs [31] because clones appear during the course of treatment those do not express the target. Therefore, additional therapeutic options are required to treat these patients. Common therapeutic mAbs against cell surface molecules exert their effects largely through immunological mechanisms, including complement-dependent cytotoxicity (CDC) and antibody-dependent cellular cytotoxicity (ADCC). ADCC and $C D C$ may not be effective for treating patients with cancer because the patients may be immunocompromised due to radiation, chemotherapy, and the malignancy itself. However, in addition to indirectly inducing Fc-dependent cell death, several mAbs possess a direct antitumor effect that induces cell arrest or programmed cell death [32, 33].

Therefore, in this study, we investigated reactivity with mesothelioma cells as well as the direct antitumor effect of the newly generated anti-mesothelioma mAbs. We found that JMAM1 and JMAM3 mAbs inhibited the proliferation of the MSTO- $211 \mathrm{H}$ mesothelial cell line, and JMAM1-4 mAbs inhibited wound closure by NCIH226 cells to varying degrees. JMAM1-4 also inhibited invasion of NCI-H226 cells to various degrees. Unfortunately, we did not identify the target molecules of JMAM1-4 mAbs. Nevertheless, the promising anti-mesothelioma activities of these antibodies warrant continued studies in vitro and in vivo that will include efforts to identify their targets. Our strategy for generating diagnostic and therapeutic mAbs specific for tumor cells differs from those of conventional methods that employ immunization with peptides or DNA. Specifically, we 


\section{a}
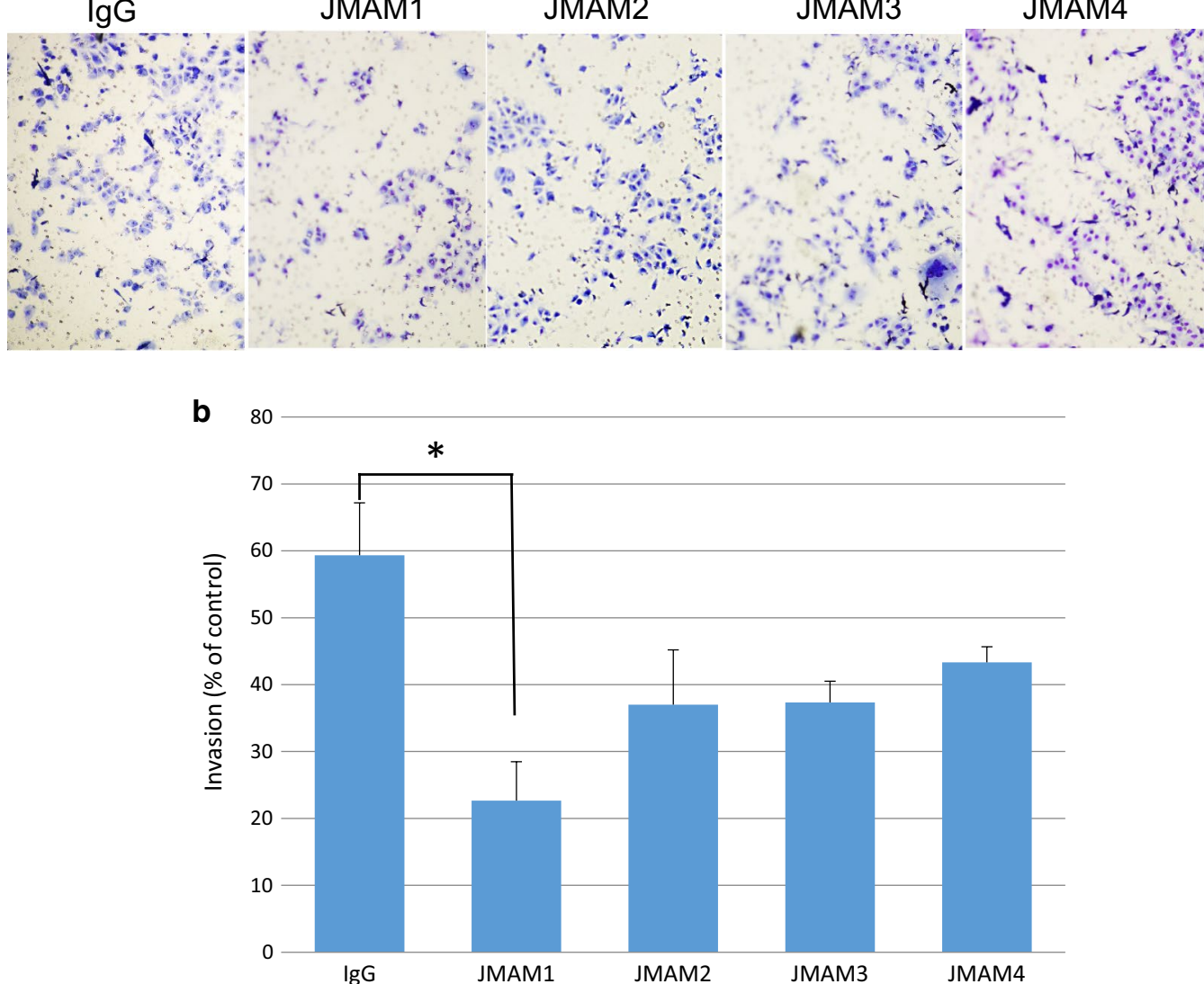

Fig. 8 Analysis of the effect of JMAM mAbs on invasion of mesothelioma cells. Cells (NCI-H226) were seeded into the upper chamber and the lower chamber was filled with medium as described in the "Methods" section. Photos were captured by a light microscope at $\times 200(\mathbf{a})$. The migration of cells was measured by counting the migrating cells on the lower surface of the membrane in 3 fields $(\mathbf{b})$. JMAM1, ${ }^{*} P<0.05 ; J M A M 2, P=0.12$; JMAM3, $P=0.08 ;$ JMAM4, $P=0.18$. Each mAb treated versus IgG control

immunized a mouse with three different mesothelioma cell lines and screened the antibodies using a different mesothelioma cell line to potentially obtain novel mAbs that react with unknown targets on the surface of mesothelioma cells.

\section{Conclusion}

Newly established anti-mesothelioma mAbs, JMAM14 , are potentially useful as diagnostic and therapeutic agents for mesothelioma. Moreover, our novel strategy for establishing anti-tumor mAbs may facilitate the development of new diagnostic and therapeutic techniques for other malignancies as well as mesothelioma.

\section{Authors' contributions}

$\mathrm{NM}, \mathrm{SM}, \mathrm{RO}$ and $\mathrm{MA}$ designed and performed experiments and wrote the paper. MW, KK and NO performed experiments. CM and OH supervised part of the experiments. All authors read and approved the final manuscript.

\section{Author details}

1 Department of Pathology, Kyorin University School of Medicine, 6-20-2, Shinkawa, Mitaka-shi, Tokyo 181-8611, Japan. ${ }^{2}$ Departments of Pathology and Oncology, Juntendo University School of Medicine, 2-1-1, Hongo, Bunkyo-ku, Tokyo 113-8421, Japan. ${ }^{3}$ Department of Pathology, Tokyo Medical University Hachioji Medical Center, 1163 Tatemachi, Hachioji-shi, Tokyo 193-0998, Japan. ${ }^{4}$ Therapy Development and Innovation for Immune Disorders and Cancers, Juntendo University School of Medicine, 2-1-1, Hongo, Bunkyo-ku, Tokyo 113-8421, Japan.

\section{Acknowledgements}

We thank Dr. T Kamei for constructive discussions, the staff of the Animal Care Committee for animal care, and the staff of the Pathology Department for their assistance in collecting body fluid samples and for consultations.

\section{Competing interests}

The authors declare that they have no competing interests.

\section{Ethics}

This study has been performed according to the principles of Helsinki and was approved by the Ethics Committee at Juntendo University School of Medicine.

\section{Funding}

S. Matsuoka received a Grant from the Japan Society for the Promotion of Science (Web: https://kaken.nii.ac.jp/d/p/15K06880.en.html, Grant Number: 15K06880).

The funders had no role in the study design, data collection and analysis, decision to publish, or preparation of the manuscript. 
Received: 20 August 2015 Accepted: 16 June 2016

Published online: 24 June 2016

\section{References}

1. Kazan-Allen L. Asbestos and mesothelioma: worldwide trends. Lung Cancer. 2005;49(Suppl 1):S3-8.

2. Robinson BW, Musk AW, Lake RA. Malignant mesothelioma. Lancet. 2005;5:397-408.

3. Carbone M, Ly BH, Dodson RF, Pagano I, Morris PT, Dogan UA, Gazdar AF, Pass HI, Yang H. Malignant mesothelioma: facts, myths and hypotheses. J Cell Physiol. 2012;227:44-58.

4. US Department of the Interior, US Geological Survey. Mineral commodity summaries 2015. 2015. p. 22-23.

5. Nguyen G, Akin MM, Villanueva RR, Slatnik J. Cytopathology of malignant mesothelioma of the pleura in fine-needle aspiration biopsy. Diagn Cytopathol. 1999;21:253-9.

6. Whitaker D. The cytology of malignant mesothelioma. Cytopathology 2000;11:139-51.

7. Fassina A, Fedeli U, Corradin M, Da FM, Fabbris L. Accuracy and reproducibility of pleural effusion cytology. Leg Med. 2008;10:20-5.

8. Pu RT, Pang Y, Michael CW. Utility of WT-1, p63, MOC31, mesothelin, and cytokeratin (CK903 and CK5/6) immunostains in differentiating adenocarcinoma, squamous cell carcinoma, and malignant mesothelioma in effusions. Diagn Cytopathol. 2008;36:20-5.

9. Chung A, Inai K, Samet J. Tumor of the pleura. In: Travis WD, Muller BE, Hermelink HK, Harris CG, editors. Pathology and genetics. Tumours of the lung, pleura, thymus and heart. Lyon: IARC Press; 2004. p. 128-42.

10. Robinson BW, Lake RA. Advances in malignant mesothelioma. N Engl J Med. 2005:353:1591-603.

11. Inai K. Pathology of mesothelioma. Environ Health Prev Med. 2008;13:60-4

12. Ordóñez NG. Immunohistochemical diagnosis of epithelioid mesotheliomas: a critical review of old markers, new markers. Hum Pathol. 2002;33:953-67

13. Ordóñez NG. Value of mesothelin immunostaining in the diagnosis of mesothelioma. Mod Pathol. 2003;16:192-7.

14. Betta P, Magnani C, Bensi T, Trincheri FN, Oreccha S. Immunohistochemistry and molecular diagnostics of pleural malignant mesothelioma. Arch Pathol Lab Med. 2012;136:253-61.

15. Takeshima Y, Inai K, Amatha V, Gemba K, Aoe K, Fujimoto N, Kato K, Kishimoto T. Accurancy of pathological diagnosis of mesothelioma cases in Japan: clinicopathological analysis of 382 cases. Lung Cancer. 2009;66:191-7.

16. Kao CS, Vardy J, Chatfield M, Corte P, Pavlakis N, Clarke C, Zandwijk NV, Clarke S. Validation of prognostic factors in malignant pleural mesothelioma. Clin Lung Cancer. 2013;14:70-7.

17. Inamoto T, Yamada T, Ohnuma K, Kina S, Takahashi N, Yamochi T, Inamoto S, Katsuoka Y, Hosono O, Tanaka H, Dang NH, Morimoto C. Humanized Anto-CD26 monoclonal antibody as a treatment for malignant mesothelioma tumors. Clin Cancer Res. 2007;13:4191-200.

18. Yamada K, Hayashi M, Du W, Ohnuma K, Sakamoto M, Morimoto C. Yamada T. cc. Cancer Cell International. 2009;9:17.

19. Köhler G, Milstein C. Continuous cultures of fused cells secreting antibody of predefined specificity. Nature. 1975;256:495-7.

20. Koprowski H, Steplewski Z, Mitchell K, Herlyn M, Herlyn D, Fuhrer P. Colorectal carcinoma antigens detected by hybridoma antibodies. Somatic Cell Genet. 1979:5:957-72.
21. Bast CR, Feeney M, Lazarus H, Nadler LM, Colvin BR, Knapp CR. Reactivity of a monoclonal antibody with human ovarian carcinoma. J Clin Invest. 1981;68:1331-7.

22. Maloney DG, Grillo-López AJ, White CA, Bodkin D, Schilder RJ, Neidhart JA, Janakiraman N, Foon KA, Liles TM, Dallaire BK, Wey K, Royston I, Davis T, Levy R. IDEC-C2B8 (Rituximab) anti-CD20 monoclonal antibody therapy in patients with relapsed low-grade non-Hodgkin's lymphoma. Blood. 1997;90(6):2188-95

23. Ishikawa K, Segawa T, Hagiwara Y, Maeda M, Abe M, Hino O. Establishment of novel monoclonal antibody to human ERC/mesothelin useful for study and diagnosis of ERC/mesothelin-expressing cancers. Pathol Int. 2009;59:161-6.

24. Lewis GD, Figari I, Fendly B, Wong WL, Carter P, Gorman C, Shepard HM. Differential responses of human tumor cell lines to anti-p185HER2 monoclonal antibodies. Cancer Immunol Immunother. 1993;37:255-63.

25. Kwee WS, Veldhuizen RW, Alons CA, Morawetz F, Boon ME. Quantitative and qualitative differences between benign and malignant mesothelial cells in pleural fluid. Acta Cytol. 1982;26:401-6.

26. Aoe K, Amatya VJ, Fujimoto N, Ohnuma K, Hosono O, Hiraki A, Fujii M, Yamada T, Dang NH, Takeshima Y, Inai K, Kishimoto T, Morimoto C. CD26 overexpression is associated with prolonged survival and enhanced chemosensitivity in malignant pleural mesothelioma. Clin Cancer Res. 2012;18:1447-56.

27. Hatano R, Yamada T, Matsuoka S, Iwata S, Yamazaki H, Komiya E, Okamoto T, Dang NM, Ohnuma K, Morimoto C. Establishment of monoclonal antihuman CD26 antibodies suitable for immunostaining of formalin-fixed tissue. Diagn Pathol. 2014. doi:10.1186/1746-1596-9-30.

28. Robinson BW, Creaney J, Lake R, Nowark A, Musk AW, de Klerk N, Winzell $P$, Hellstrom KE, Helstrom I. Mesothelin-family proteins and diagnosis of mesothelioma. Lancet. 2003;362:1612-6.

29. Hellstrom I, Raycraft J, Kanan S, Sardesai NY, Verch T, Yang Y, Hellstrom KH. Mesothelin variant 1 is released from tumor cells as a diagnostic marker. Cancer Epidemiol Biomark Prev. 2006:15:1014-20.

30. Scholler N, Fu N, Yang Y, Ye Z, Goodman GE, Hellstrom KE, Hellstrom I. Soluble member(s) of the mesothelin/megakaryocyte potentiating factor family are detectable in sera from patients with ovarian carcinoma. Proc Natl Acad Sci USA. 1999;6:11531-6.

31. O'Brien SM, Kantarjian H, Thomas DA, Giles FJ, Freireich EJ, Cortes J, Lemer S, Keating MJ. Rituximab dose-escalation trial in chronic lymphocytic leukemia. J Clin Oncol. 2001:19:2165-70.

32. Matsuoka S, Asano Y, Sano K, Kishimto H, Yamashita I, Yorifuji H, Utsuyama M, Hirokawa K, Tada T. A novel type of cell death of lymphocytes induced by a monoclonal antibody without participation of lymphocytes. J Exp Med. 1995:181:2007-15.

33. Yuniel FM, Alejandro LR. Lonely killers. mAbs. 2008;3:528-34.

\section{Submit your next manuscript to BioMed Central and we will help you at every step:}

- We accept pre-submission inquiries

- Our selector tool helps you to find the most relevant journal

- We provide round the clock customer support

- Convenient online submission

- Thorough peer review

- Inclusion in PubMed and all major indexing services

- Maximum visibility for your research

Submit your manuscript at www.biomedcentral com/submit 